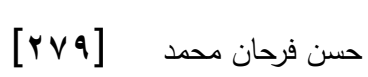

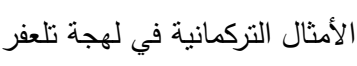

\author{
الأمثال التركمانية في لهجة تلعفر: الزواج أنموذجا \\ حسن فرحان محمد \\ مدرس مساعد، كلية الآداب جامعة الموصل معل
}

خلاصة البحث

إن الأمثال الثعبية من الشمول ما يجعل الإحاطة بها عملا صعبا لا يمثله بحث

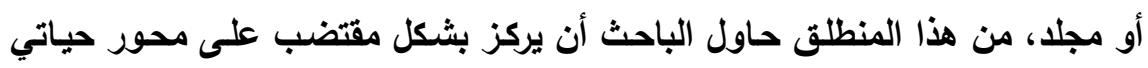

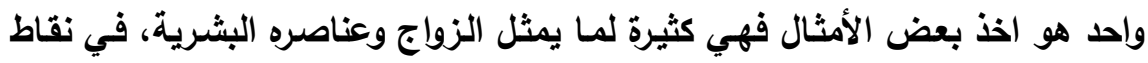

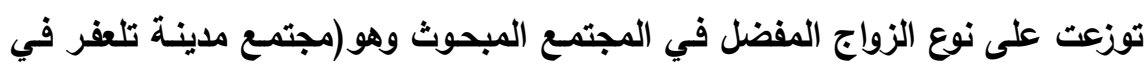

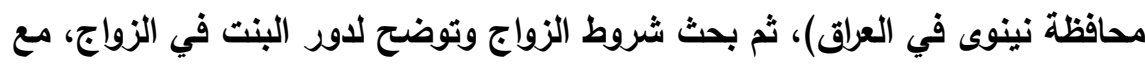

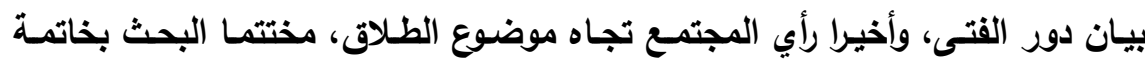
موضوعه.

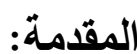

تعد الأمثال الثعبية ومضات فكرية واجتماعية تحمل إلينا العبرة المفيدة

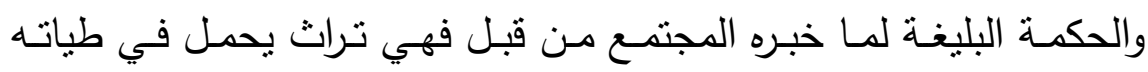

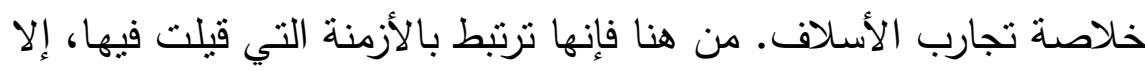

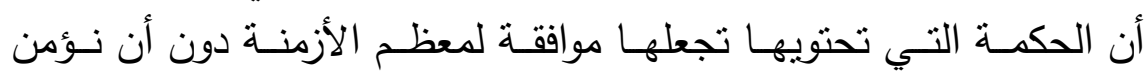

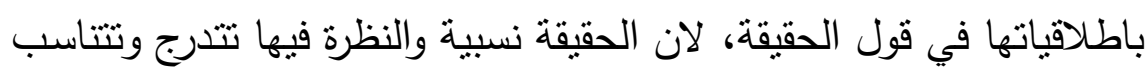

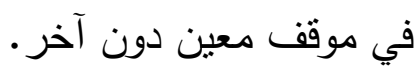




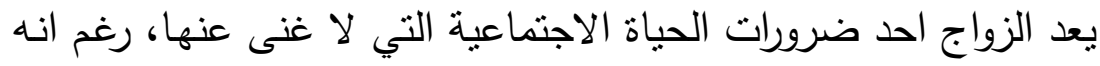

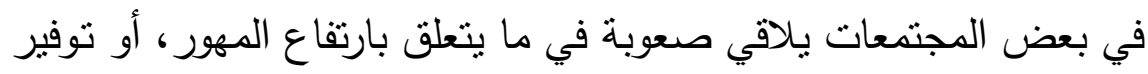
السكن المستقل.. وما شاكل من معوقات واخذ المجتمع على عاتى عاتقه الاهتمام

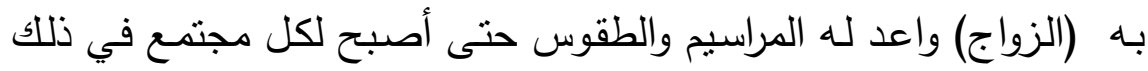
مذهب خاص يحترم ويراعى. انسه على وفـق تــوع المجتمعـات في نقافتهـا، وتباينها في في أنماطهـا

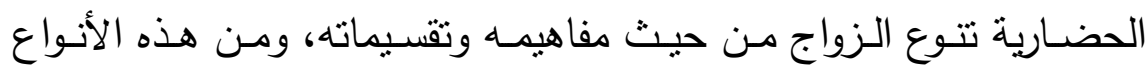

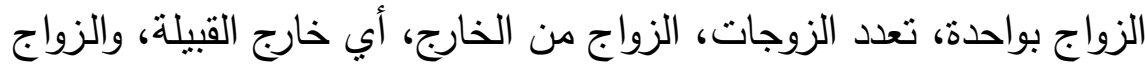

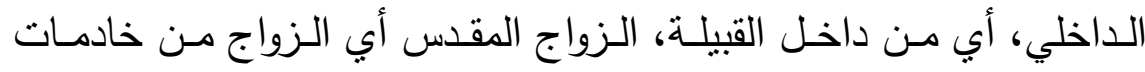

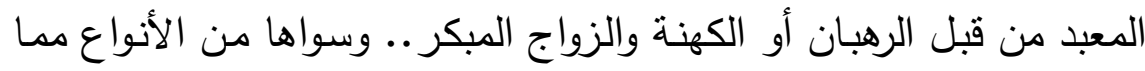
ليس محل ذكره هنا.

وكل نقافة تعبر عن تفضيلها لنوع ما من أنواع الزواج الأنفة الذكر

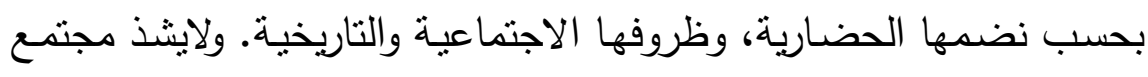

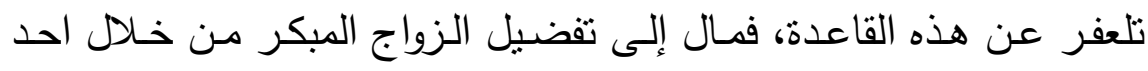

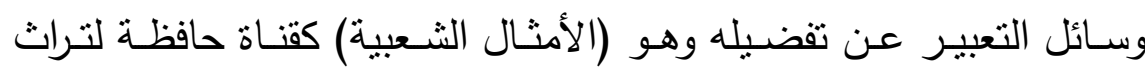

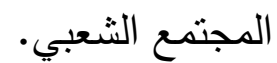

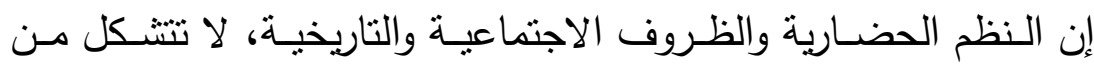

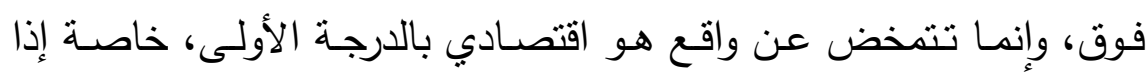

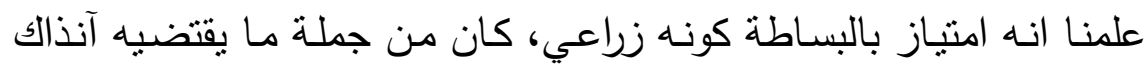

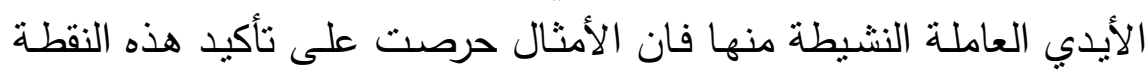

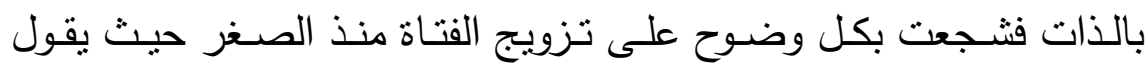
الهتل"فيزي كوجوك ايكن كيش يه وير "فضلا عن هذا المثل" وسواهما من 
الأمثنال التي تحساول أن تؤكد مـا أسـلفنا قولـه، حول دواعي قيـام الزواج

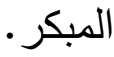

إن الإنسان كما يذهب علم النفس والاجتماع كائن تبريري، فهو دائما ما

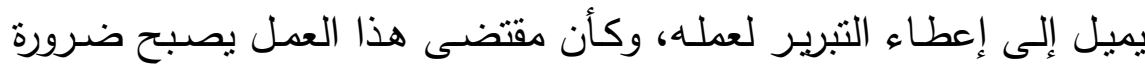

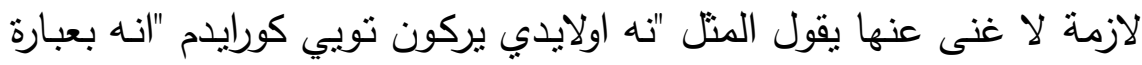

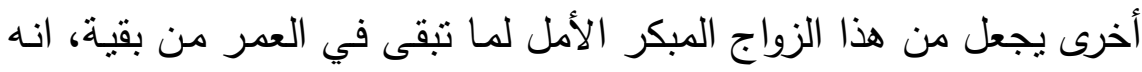

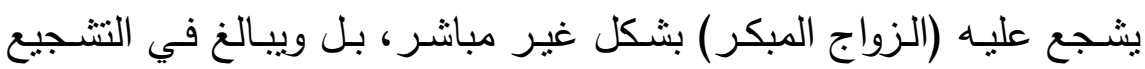

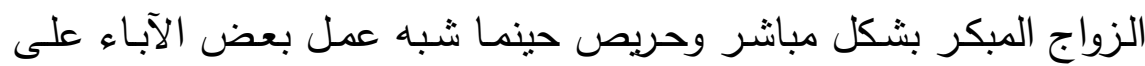

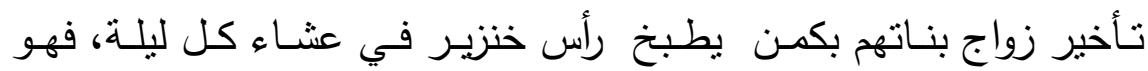

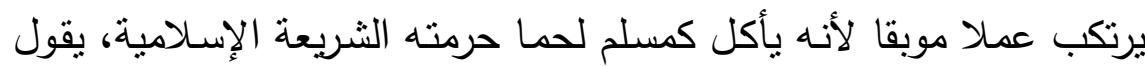
المتل "قيزك ايولنماغي كيجرسه بباسي كيجة ده بردويز بانثي بشرير ".

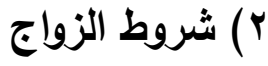

حين فضل المجتمع (التلعفري) الزواج المبكر على بقيـة أنواع فـان

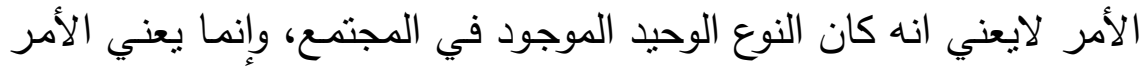

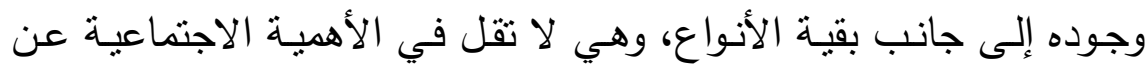

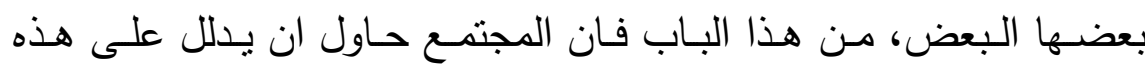

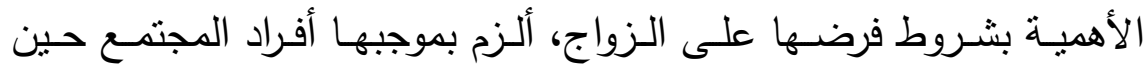

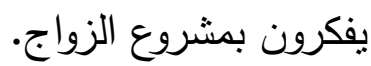

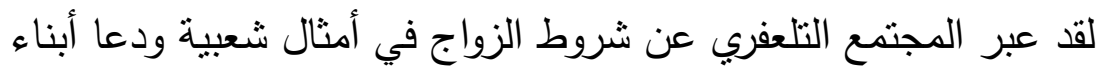

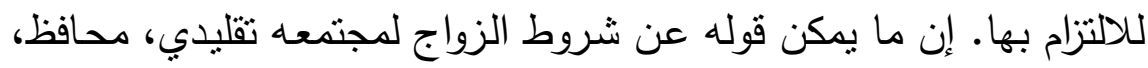

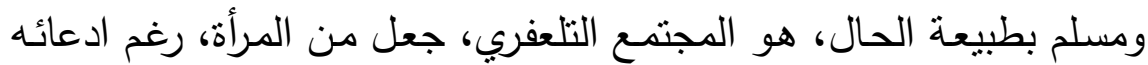

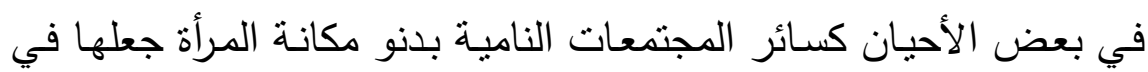

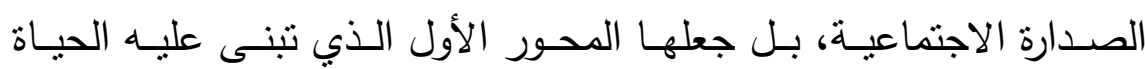




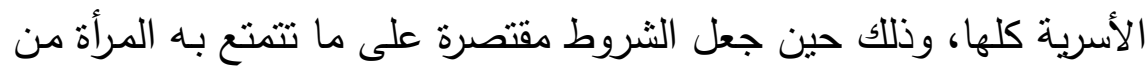

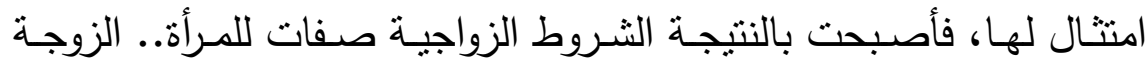

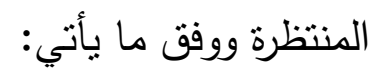
(') صفات نسبية (الأصل والنسب) يقول المثل الأتي معبرا عنها بالقول

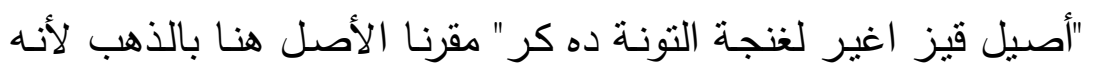

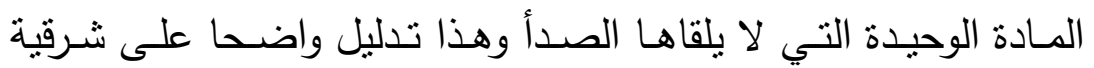
المجتمع التلكفري المؤكدة دوما على الأصل والنسب.

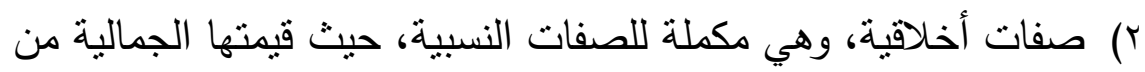

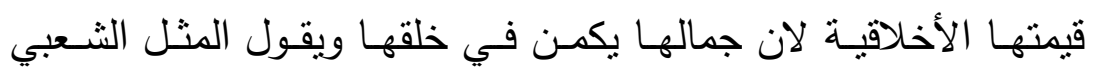

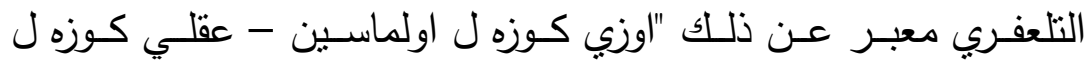

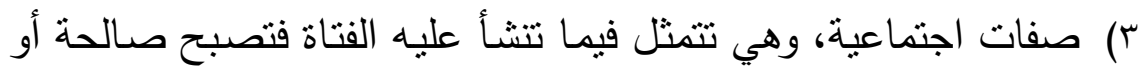
غير صالحة، وللام كما هو معلوم دور بارز في هذه التنشئة، من هنا

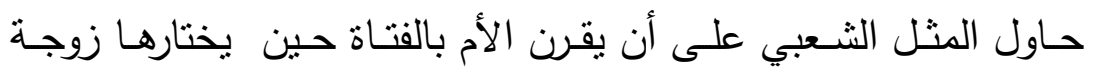

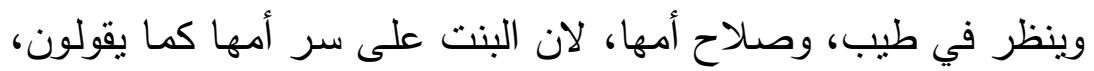

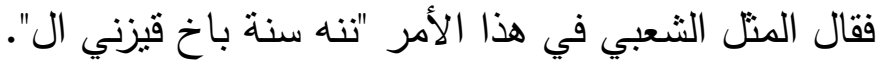

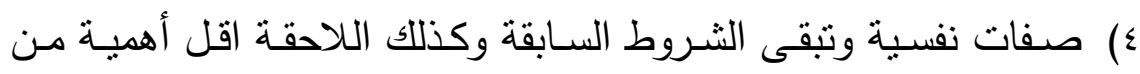

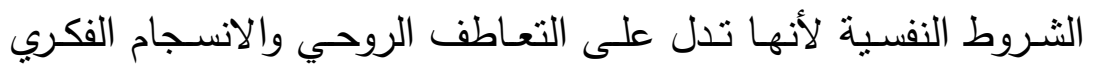

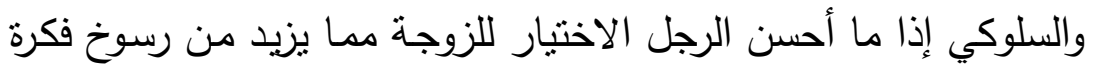

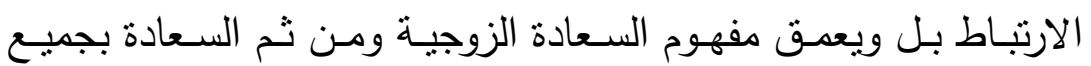

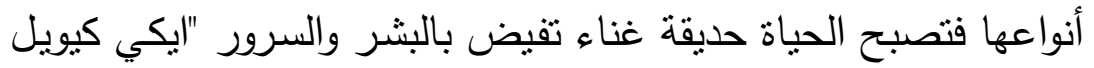
بر اولسة صماننخ (صمانلغ) سيران اولور .

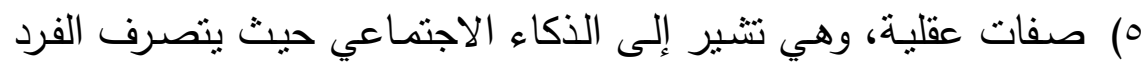

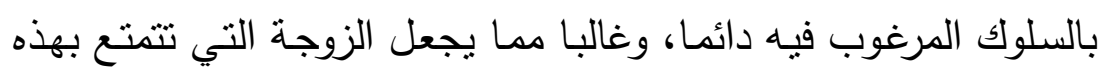




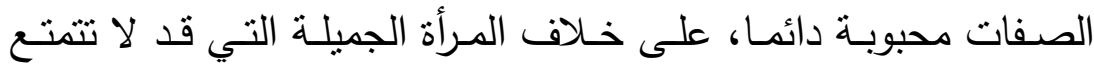

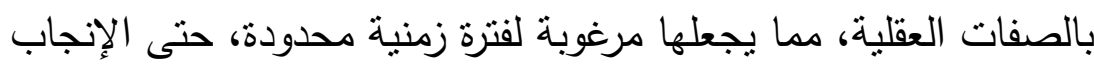

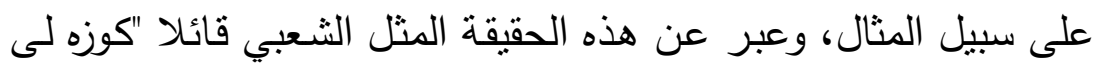
سيوه للر ايوه كيجنجا - عاقلي سيوه للر اولب كيدنجا".

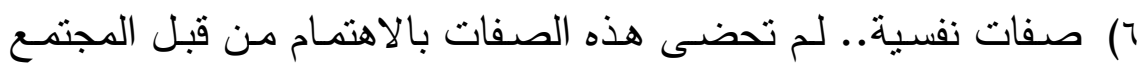

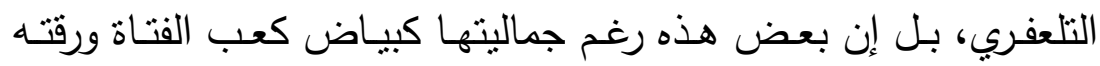

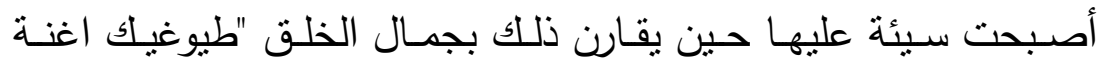

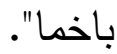

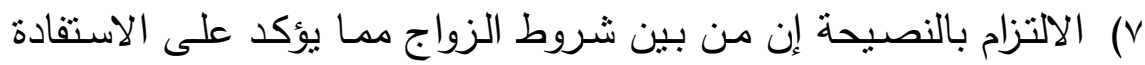

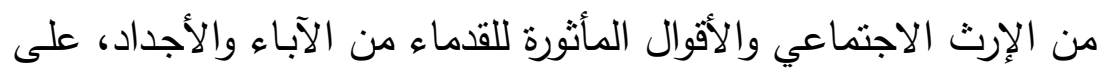

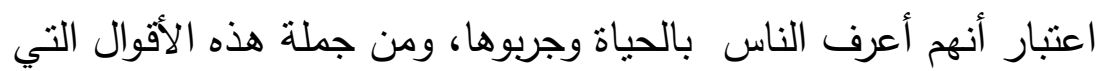

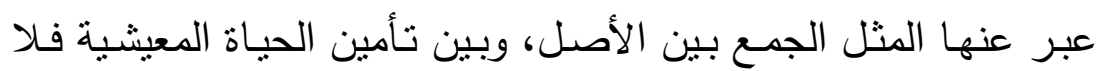

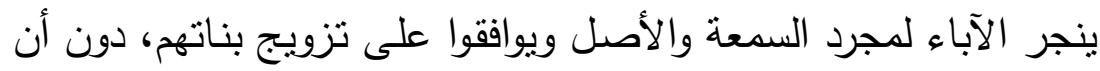

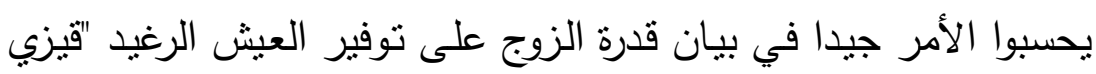

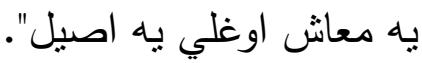

\section{باء (بور البنت في الزواج}

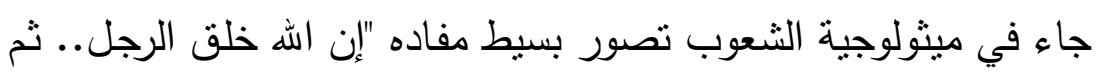

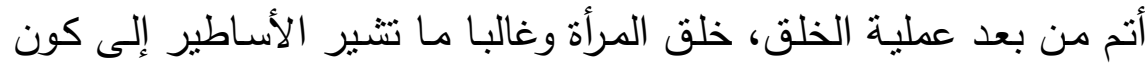

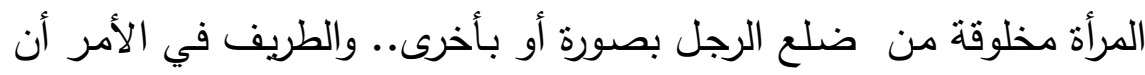

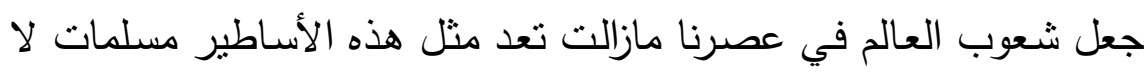

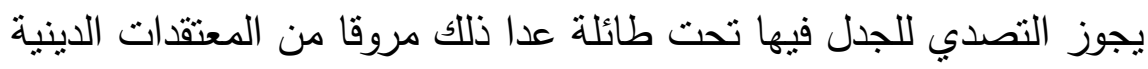

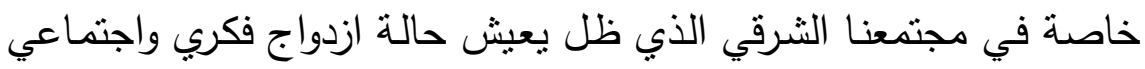

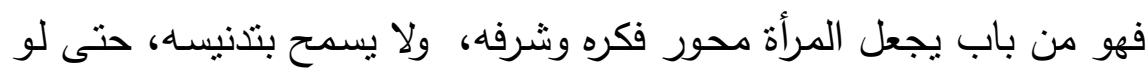


اقتضى ذلك أن يقدم نفسه ضحية لكلمة قيلت في شرف ابنته أو زوجته، وهو من باب آخر سلب منها حريتها وعاملها بازدراء.

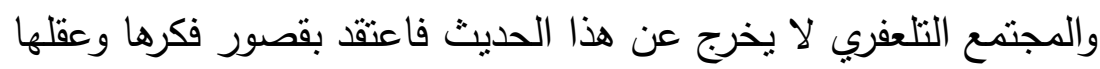

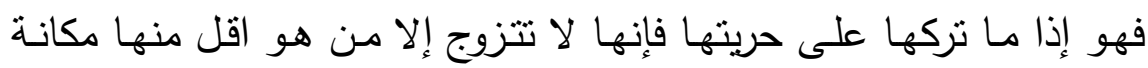

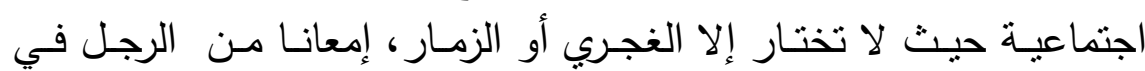

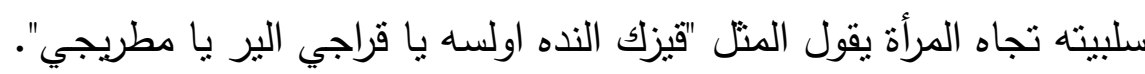

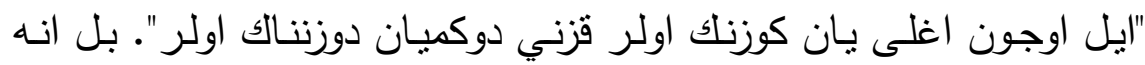

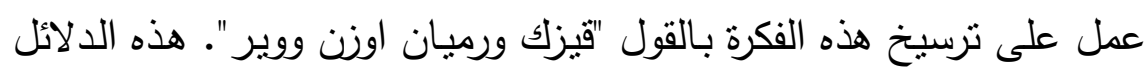

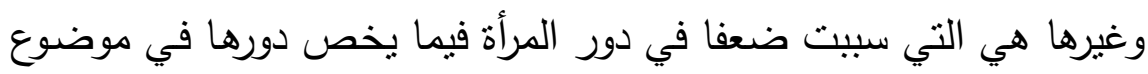

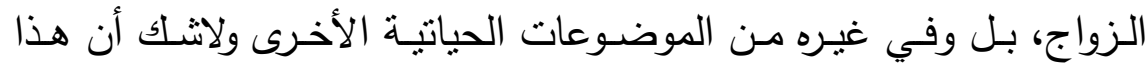

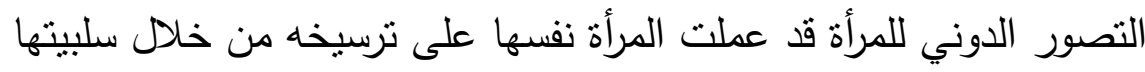

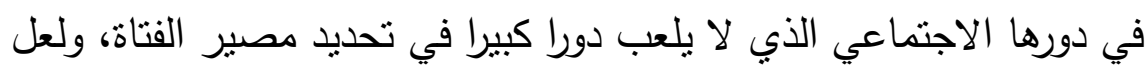

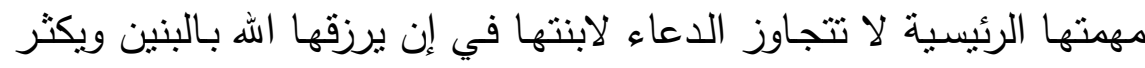
من عددهم "ييدي اوغلان ننه سي اولايدي".

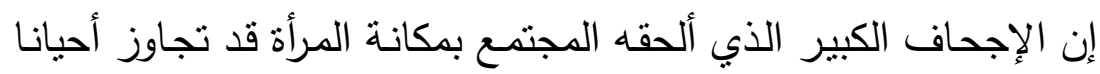

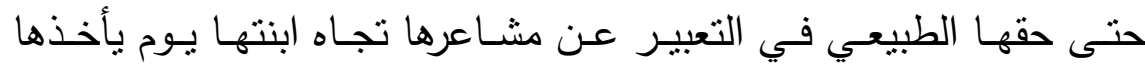

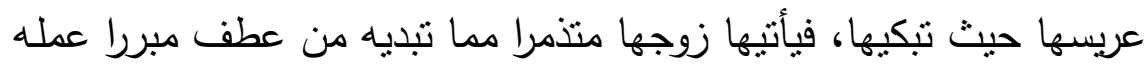

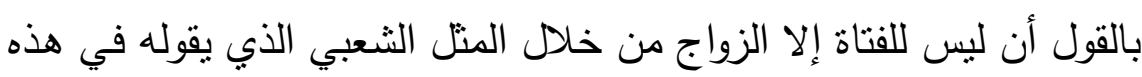

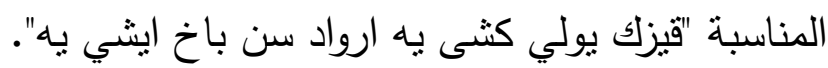

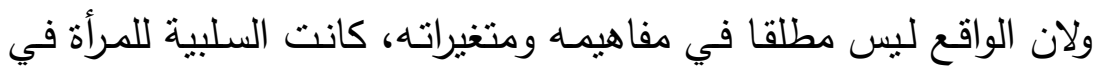

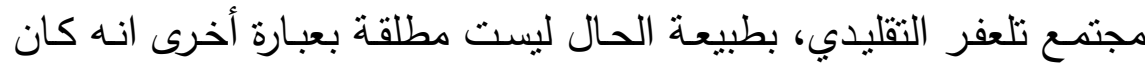

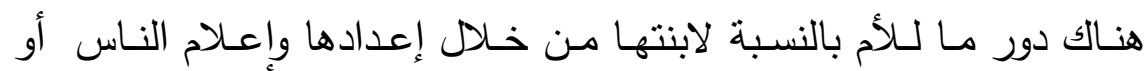

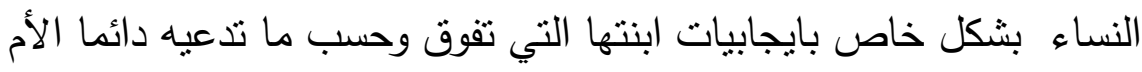

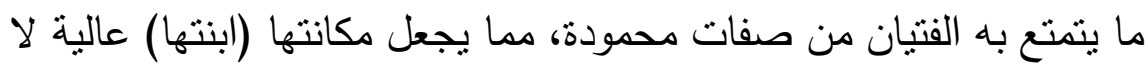


تبدلها بمكانة الفتيـان الاجتماعية العالية لأبناء الآخرين، وتعبر عن ذلك

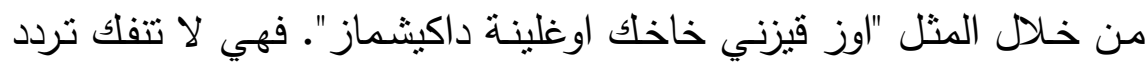

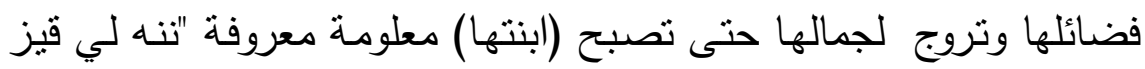

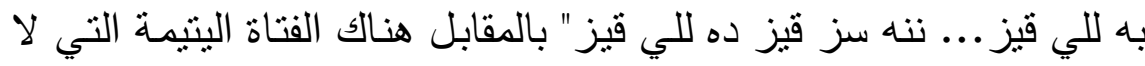

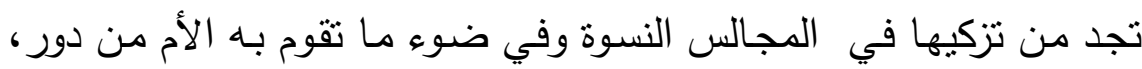
فإننا نجد دائما هناك صراع اجتماع بين الأمهات وبلغة المجتمع ما نسميه

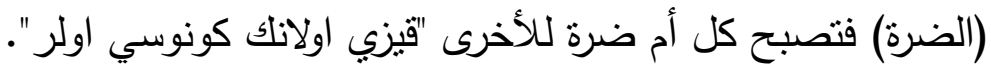

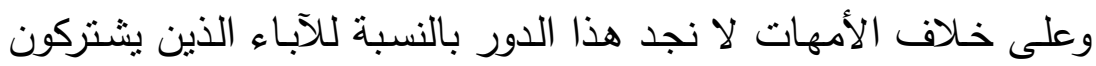

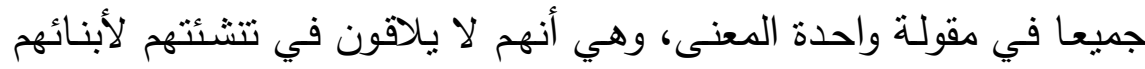
بنينا وبناتا إلا الثقاء والتعب حيث ذهب واهي عمرهم تدريجيا دون أن يحسوا به "

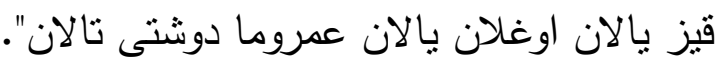

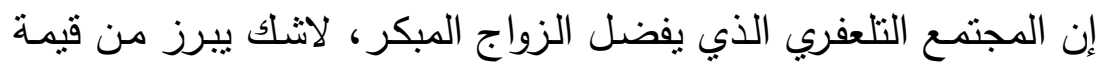

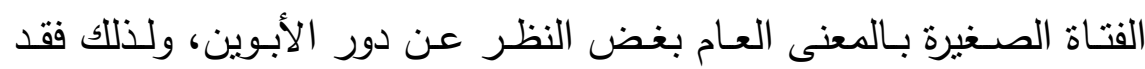

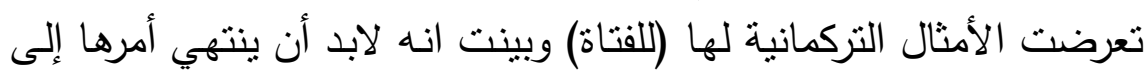

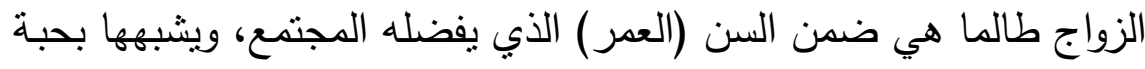

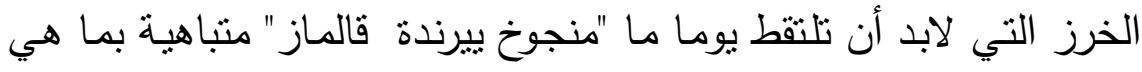

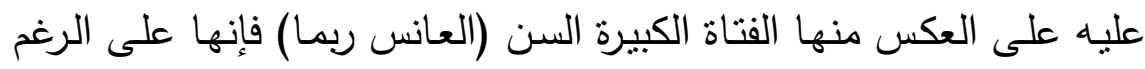

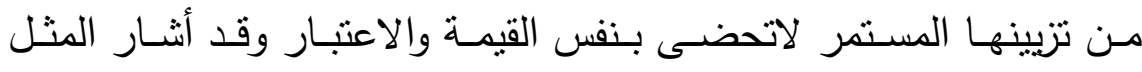
الشعبي إلى ذلك بالقول "قاري قيز بزاننجه توي بطال اولر".

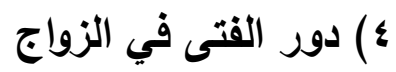

على الرغم من كثرة الأمثال الثعبية التركمانية التي تعرضت للفتاة، فإننا لا نلمس ذلك بالنسبة للفتى، وقد يكون سبب ذلك هو الدور الرئيسي للوالدين

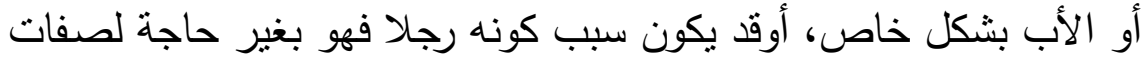

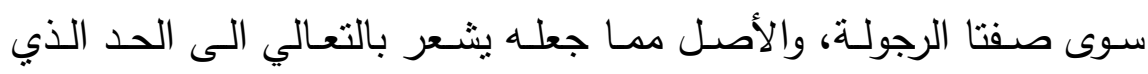


يتصور إن من حقه أن يتطاول حتى بالضرب على الفتاة (زوجة المستقبل)

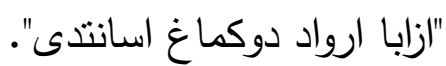
إن هذا التصـور للفتى ليس بالغريب فهولا يقوم بهذا السلوك إلا تأثرا

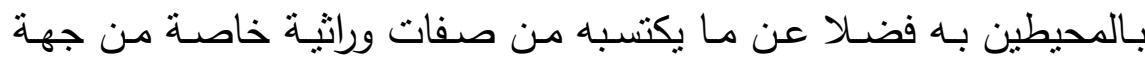
النسـاء. ولهذا السبب ولأسباب أخرى ليس هذا مكان بحثنها دخل المنل الثعبي مباشرة إلى تصوير حالة الفتى، ضمن مراسيم الزفاف على لـى العكس

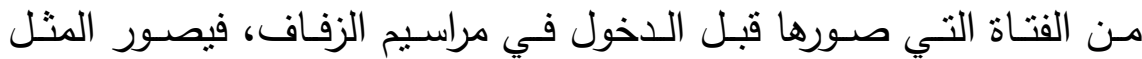

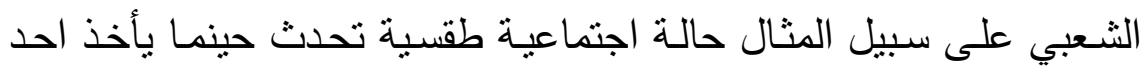

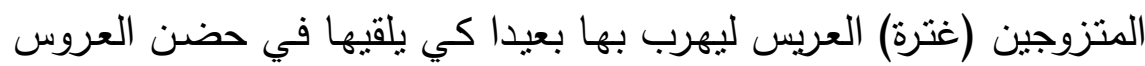

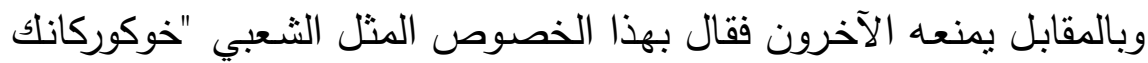

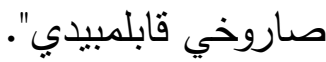
إن مصادر دور الفتى في موضوع الزواج قد يصل إلى حد الخوف عليه

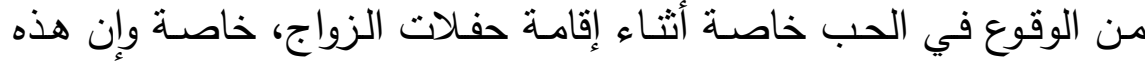

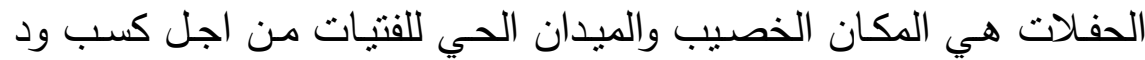

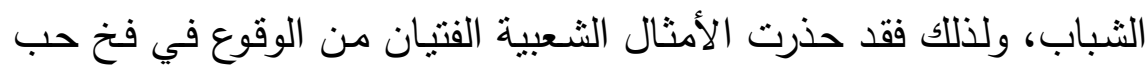
حفلات الأعراس "تويده قيز سيومة".

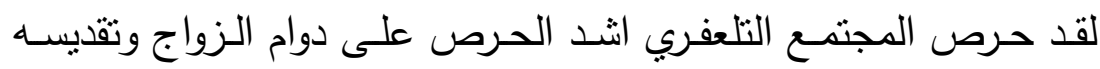

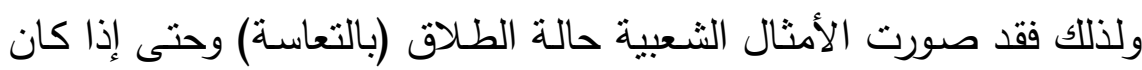

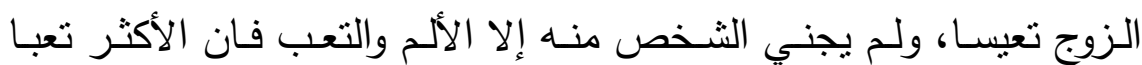

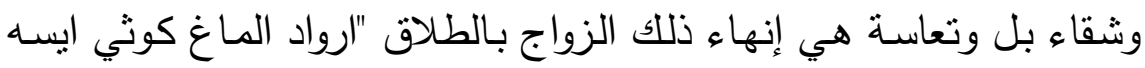

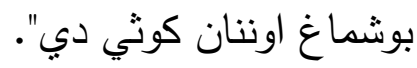




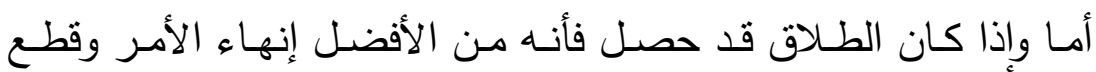

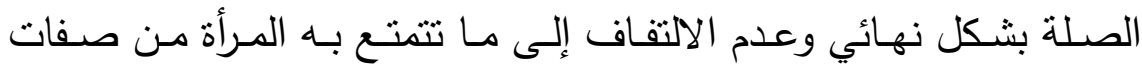
ايجابية خلقية أو جسمية "ارواد بوشيان توبيغنك اغنه باخماز ".

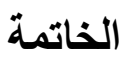

لقد مثلت الأمثال الثعبية أصدق تمثل ثقافة المجتمع ومعرفته لتمثيلها

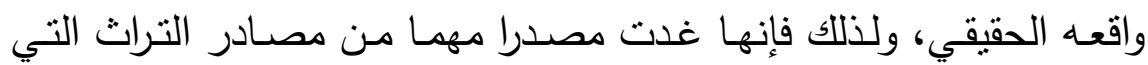

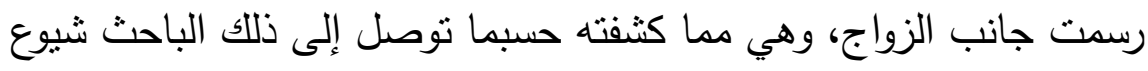

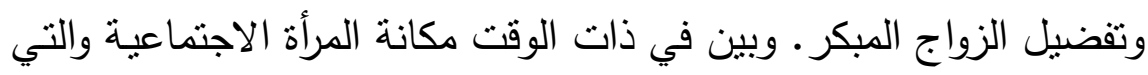

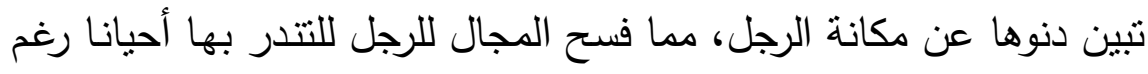

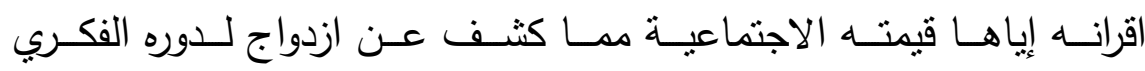

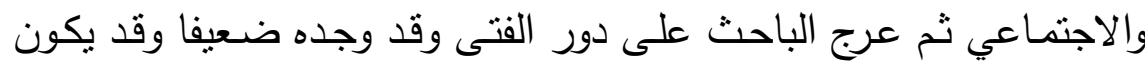

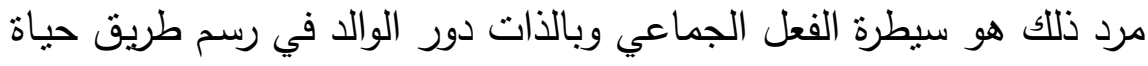

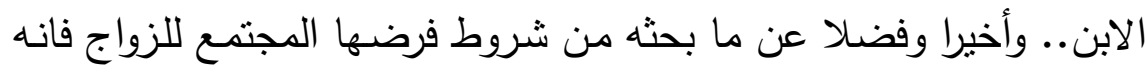

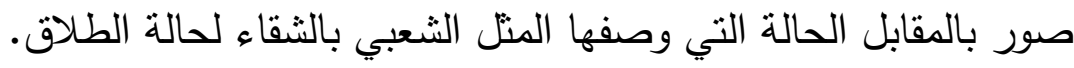

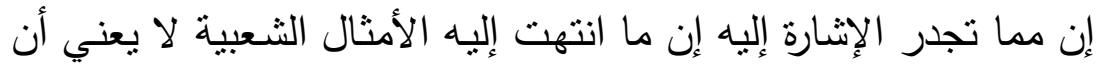

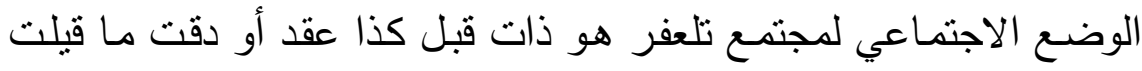

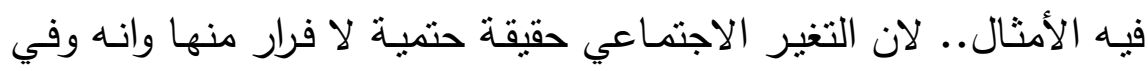

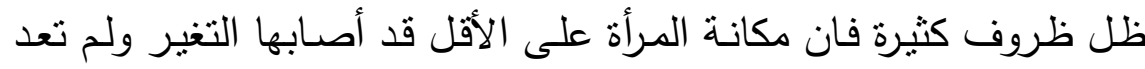

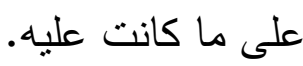

\title{
Turkuman Proverbs In Talafar Tung
}

\author{
Hasan Frashan Mrohmmed

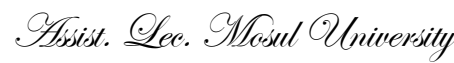


$(1 \wedge)$ T

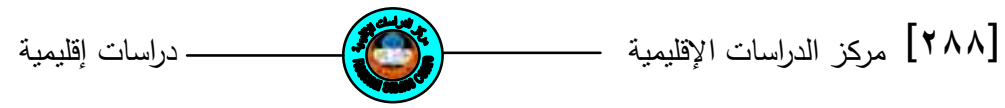

\begin{abstract}
The popular proverbs has represented the most truthful representation of both society culture and knowledge, for its actual reality; therefore it became one of the main sources of heritage which drew one its sides that is marriage.

This side has revealed as the researcher has reached during his study ,the publicity and preference of early marriage, and during that time this has showed the woman's social position that is lower than man, and it enabled the man to make joke of her in front of his peers ,by which it revealed his duplicity in both intellectual and social role.

The researcher in this paper has showed the weak role of the young person and this is due to the dominance of the collective team action, especially the father's role in drawing the path of his son's life ,and at last, in addition to what the researcher has studied about the conditions that the society has imposed ,but it pictured in return the divorce as misery in the popular proverb.

What should be referred to is that popular proverbs doesn't mean that the social position of Talafar society is the same in the previous decades because the changeable society is a determinism fact with no escape from and in many circumstances the woman's position has changed and did not remain as it is.
\end{abstract}

$$
\text { (1) }
$$




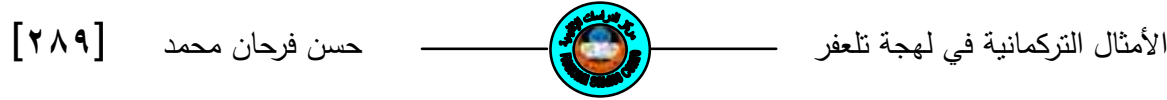

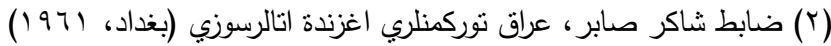

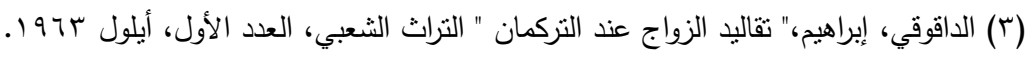

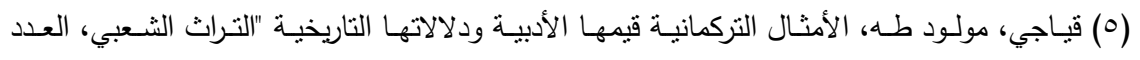

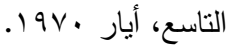

$$
\begin{aligned}
& \text { (7) مسلم عدنان احمد محاضرات في الانتروبولوجية (الرياض. د.ت). } \\
& \text { ثانيا: المصادر التركية: } \\
& \text { ثالثا: المقابلات الثخصية }
\end{aligned}
$$

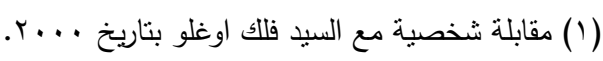

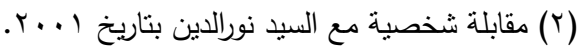

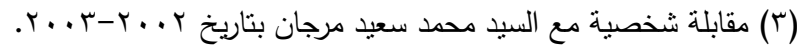

